\title{
Financial Flow Variables and the Short-Run Determination of Long-Term Interest Rates
}

\section{Citation}

Friedman, Benjamin Morton. 1977. Financial flow variables and the short-run determination of long-term interest rates. Journal of Political Economy 85(4): 661-689.

\section{Published Version}

doi:10.1086/260595

\section{Permanent link}

http://nrs.harvard.edu/urn-3:HUL.InstRepos:4554309

\section{Terms of Use}

This article was downloaded from Harvard University's DASH repository, and is made available under the terms and conditions applicable to Other Posted Material, as set forth at http:// nrs.harvard.edu/urn-3:HUL.InstRepos:dash.current.terms-of-use\#LAA

\section{Share Your Story}

The Harvard community has made this article openly available.

Please share how this access benefits you. Submit a story.

Accessibility 


\title{
Financial Flow Variables and the Short-Run Determination of Long-Term Interest Rates
}

\section{Benjamin M. Friedman}

Harvard University

\begin{abstract}
Because transactions costs are smaller for allocating new cash flows than for reallocating existing asset holdings, financial flow variables are important determinants of investors' short-run asset demands. The demandfor-bonds equations implied by the resulting "optimal marginal adjustment" model of portfolio behavior constitute the demand side of a structural supply-demand model of the determination of the long-term interest rate. Empirical results, based on demand-for-bonds equations estimated using U.S. data for six major categories of bond market investors, support the optimal marginal adjustment model and show that the associated structural model of interest rate determination, which is restricted by the underlying demand-for-bonds equations, fits the data about as well as do previously developed unrestricted reduced-form term-structure equations.
\end{abstract}

The analytical frameworks which economists use to investigate various economic phenomena often bear little resemblance to market participants' conceptions of the processes in which they play some role. A striking example of this dichotomy is the question of how long-term interest rates are determined. Financial market participants, keenly sensitive to the fact that the immediate determination of bond yields takes place in a market in which securities are bought and sold, typically believe that the interplay between borrowers' issues of new bonds and investors' newly available cash flows represents an important determinant

The author is grateful to Kenneth Froewiss and Vance Roley for research assistance and to Gary Chamberlain, James Duesenberry, Patric Hendershott, Kenneth Froewiss, John Lintner, Franco Modigliani, Vance Roley, Robert Shiller, Allen Sinai, Gary Smith, and an anonymous referee for helpful comments on previous drafts of this paper. The author also gratefully acknowledges the National Science Foundation's support of the main part of this research, under grant SOC74-21027, and the National Bureau of Economic Research's support of computation done on its TROLL system.

[Journal of Political Economy, 1977, vol. 85, no. 4]

(C) 1977 by The University of Chicago. All rights reserved. 
of long-term yields. In contrast, most economists have placed almost exclusive emphasis on the role in portfolio selection of relative asset returns and risks, which lead to reduced-form equations incorporating term-structure and price-expectations elements and have argued that, if quantity variables are relevant at all, it is not flows but stocks which matter. ${ }^{1}$

The object of this paper is to set forth and estimate, using U.S. data, a framework which reconciles these two conflicting views about the importance, or lack of importance, of financial flow variables in the determination of long-term interest rates. In particular, in the framework presented below, flow variables are important determinants of the shortrun variation of long-term yields, while in the long run only stock variables and relative return and risk variables matter.

The vehicle which this paper uses to explore this question is a structural model of the determination of long-term interest rates, as previously described in some detail in Friedman (1974). The primary thrust of this model is to eschew the familiar unrestricted reduced-form term-structure equation and to use instead a set of structural equations representing supplies of and demands for long-term bonds. Since each such supply or demand equation is a function of the long-term bond yield, among other variables, the addition of a market-clearing identity equating total net excess supply (demand) to zero facilitates solving the model for the long-term bond yield itself. The principal usefulness of this structural model, for the purpose of this paper, is that it provides a way of focusing directly on those aspects of investors' behavior which lead to the short-run importance of financial flow variables. The form of the model presented in this paper is consistent with this orientation, in that it develops the role of the flow variables in detail but does not incorporate either complex lag structures on yield variables or a wide variety of exogenous variables other than straightforward asset return variables; such extensions remain for further research. ${ }^{2}$

Section I develops the basic framework of portfolio selection and portfolio adjustment, an "optimal marginal adjustment" model, within which financial flow variables play an important role in the determination

${ }^{1}$ Culbertson's (1957) "market segmentation" views are something of an exception in their adaptability to the association of causal influence with flow variables. The work by Modigliani and Sutch $(1966,1967)$ and Modigliani and Shiller $(1973)$ bears the label "preferred habitat" theory and therefore seems at first glance to allow for the role of flow variables, but no such variables appear in the empirical work. Silber (1970), Hendershott (1971), Bosworth and Duesenberry (1973), and Hendershott and Lemmon (1973) have introduced flow variables into their empirical models, but they have done so without providing an explicitly specified analytical framework to show why these variables are present.

${ }^{2}$ See Friedman (1974) for a discussion of lag structures and of exogenous variables which may play a role in determining investors' demands for bonds. Friedman (1976) uses such lag structures in empirical work on the supply of bonds by corporations. 
of the short-run behavior of investors' asset demands. Section II briefly reviews the basic features of the overall structural model of long-term interest rate determination as used in this paper. Section III discusses some operational questions of estimation procedure and data. Section IV presents results for equations representing the demand for long-term bonds by the six major categories of investors in the U.S. corporate bond market, commenting in particular on the implications of the estimation results for the role of financial flow variables in influencing portfolio behavior. Section V presents two sets of full-system dynamic simulation results: for the seven-equation structural model consisting of the six estimated demand-for-bonds equations and a market-clearing identity (with bond supply taken as exogenous), and for the analogous nineequation model incorporating the two supply-of-bonds equations developed in Friedman (1976). Section VI briefly summarizes the main conclusions of the paper.

\section{The "Optimal Marginal Adjustment" Model of Portfolio Behavior}

In a world in which transactions costs are nontrivial, it is useful to represent investors' portfolio behavior by a model which determines the desired long-run equilibrium portfolio allocation together with a model which determines the short-run adjustment toward the equilibrium allocation.

A familiar model of the selection of desired portfolio allocation, for a given investor or group of investors, is the linear homogeneous form ${ }^{3}$

$$
\frac{A_{i t}^{*}}{W_{t}}=\sum_{k}^{N} \beta_{i k} r_{k t}+\sum_{h}^{M} \gamma_{i h} X_{h t}+\pi_{i}, \quad i=1, \ldots, N,
$$

where

$$
\begin{aligned}
A_{i t}^{*}, i=1, \ldots, N= & \text { the investor's desired equilibrium holding of the } \\
& \begin{aligned}
& \text { th asset at time period } t\left(\sum_{i} A_{i t}^{*}=W_{t}\right) \\
& W_{t}= \text { the investor's total portfolio size (wealth) at time } \\
& \text { period } t ;
\end{aligned} \\
r_{k t}, k=1, \ldots, N= & \text { the expected holding-period yield on the } k \text { th asset } \\
& \text { at time period } t ; \\
X_{h t}, h=1, \ldots, M= & \text { the values at time period } t \text { of additional variables } \\
& \text { which influence the portfolio allocation; }
\end{aligned}
$$

${ }^{3}$ Asset stocks and wealth are measured on an end-of-period basis throughout. See, for example, de Leeuw (1965), Brainard and Tobin (1968), and Hendershott (1971). Linear homogeneous asset demand functions may be derived from, for example, maximization of a negative exponential utility function in portfolio rate of return, where asset returns are normally distributed. 
and the $\beta_{i k}, \gamma_{i h}$, and $\pi_{i}$ are fixed coefficients which satisfy $\sum_{i} \beta_{i k}=0$ for all $k, \sum_{i} \gamma_{i h}=0$ for all $h$, and $\sum_{i} \pi_{i}=1$. The role of the wealth homogeneity constraint is to require that any shift in an asset's share in the desired equilibrium portfolio be due to movements either of relevant yields $\left(r_{k}\right)$ or of other variables $\left(X_{h}\right)$, rather than to overall growth of the total portfolio itself; particularly for the case of equations representing the behavior of categories of investors, this assumption seems appropriate. ${ }^{4}$

The analytical role of the expected holding-period yield variables, $r_{k}, k=1, \ldots, N$, is straightforward, although devising ways of empirically representing these expectations is highly complicated when potential capital gains or losses are involved. The usual presumption is that investors' demand for any asset responds positively to the own yield on that asset $\left(\beta_{i k}>0, k=i\right)$ and negatively to the yields on alternative assets $\left(\beta_{i k}<0, k \neq i\right)$. Because of differing portfolio objectives in terms of return and risk, differing effective transactions costs, and differing institutional and regulatory constraints, the group of assets which compete for a place in the collective portfolio of any investor or group of investors need not coincide with the entire menu of assets available in the economy. In practice, therefore, it is necessary to determine what potential substitutabilities are actually relevant in each case, and portfolio selection equations for different investor categories need not include identical groups of yield variables. ${ }^{5}$

The variables $X_{h}, h=1, \ldots, M$, in the portfolio selection model (1) represent influences, other than the $r_{k}$ measures of expected holding-period yields, which cause investors to change their desired equilibrium portfolio allocations among the various available assets. Following the meanvariance model of portfolio selection, these additional variables represent influences on investors' perceptions of return (to the extent that measures $r_{k}$ are incomplete) and risk over the relevant holding period. Some investors may respond to certain specific influences, such as the anticipated volatility of nominal returns, while other investors may respond to different influences, such as anticipated price inflation. As is the case for the yield variables, therefore, portfolio selection equations for different investor categories need not include identical groups of nonyield variables.

Given the desired equilibrium portfolio allocation indicated by model (1), the usual description of investor behavior involves a shift of asset

\footnotetext{
${ }^{4}$ For a further discussion of the rationale behind the wealth homogeneity constraint, see Friedman (1956) and de Leeuw (1965). For an alternative view, see Goldfeld (1966, 1969).

${ }^{5}$ In principle, of course, a sufficiently extreme return on any asset could bring about substitutions which do not normally take place. Nevertheless, the possibility that some individuals may buy private-placement bonds at a 25 percent yield, for example, does not warrant including the private-placement yield in equations for individuals' asset demands if that yield has varied only between 5 percent and 15 percent during the relevant sample period.
} 
holdings which eliminates some, but not all, of the discrepancy between holdings $A_{i, t-1}$ at the end of the previous period and the new desired holdings $A_{i t}^{*}$. One familiar representation of the resulting portfolio adjustment process is the stock adjustment model $^{6}$

$$
\Delta A_{i t}=\sum_{k}^{N} \theta_{i k}\left(A_{k t}^{*}-A_{k, t-1}\right), \quad i=1, \ldots, N,
$$

where $A_{i t}=$ the investor's actual holding of the $i$ th asset at time period $t$ $\left(\sum_{i} A_{i t}=W_{t}\right)$, and the $\theta_{i k}$ are fixed coefficients of adjustment such that $0 \leq \theta_{i k} \leq 1, k=i$, and $\sum_{i} \theta_{i k}=1$ for all $k$. An analogous model which involves explicit adjustment of the portfolio proportions is

$$
\Delta \alpha_{i t}=\sum_{k}^{N} \theta_{i k}\left(\alpha_{k t}^{*}-\alpha_{k, t-1}\right), \quad i=1, \ldots, N
$$

where

$$
\alpha_{i t} \equiv \frac{A_{i t}}{W_{t}}, \quad\left(\sum_{i} \alpha_{i t}=1\right)
$$

and the constraint applicable to the $\theta_{i k}$ is the weaker $\sum_{i} \theta_{i k}=\bar{\theta}$ for all $k$ (which does not require $\bar{\theta}=1$ ).

At least three conceptually distinct phenomena may account for investors' failure to adjust their portfolios fully and immediately to whatever equilibrium allocations are consistent with each period's new values of the relevant variables: transactions costs, expectation formation lags, and perception lags. The lags associated with forming expectations and with perceiving current market developments in large part give rise empirically to the use of distributed lags on market yields to represent the expected holding-period yield variables $\left(r_{k}\right)$ in portfolio selection model (1). ${ }^{7}$ In contrast, the lags associated with transactions costs are of key importance to this paper's concern with the role of financial flow variables.

Transactions costs in the U.S. long-term debt markets take the form either of direct pecuniary charges or more indirect costs. Direct pecuniary charges include such factors as bid/asked spreads for institutional investors in the professional dealer market for debt securities and, in addition, brokerage fees for individual investors. Indirect costs for institutional investors include increased in-house overhead expenses associated with greater trading activity and participation in specialized forms

\footnotetext{
${ }^{6}$ Anderson (1964), de Leeuw (1965), and Goldfeld (1966) are a few examples of the application of the stock adjustment model to portfolio behavior. As Smith (1975) has pointed out, it is necessary to interpret each $\theta_{i k}$ as the partial effect on $A_{i}$ of a unit increase in $A_{k}^{*}$ accompanied by a unit increase in $W$.

${ }^{7}$ See Friedman (1974) for further discussion of these two sources of lagged adjustments.
} 
of transactions, while for individual investors the most important factor is probably the opportunity cost of whatever time trading absorbs. Gathering and processing information may be a major component of the cost of trading for both institutions and individuals. Transactions costs also differ among types of debt securities. The bid/asked spread in the Treasury bill market, for example, is smaller than the spread for a trade of comparable size in the long-term bond market. Transactions cost distinctions at various levels exist even within the overall classification of long-term corporate bonds, as new issue purchases differ from secondary market trading, and privately placed securities usually tend to be highly illiquid. ${ }^{8}$ Indirect transactions costs, such as the difficulty of obtaining rapid execution of a trade, also vary considerably from one type of security to another.

One implication of these transactions costs is that it is easier (cheaper) for most investors to allocate new cash flows-including both net wealth increments and repayments such as dividends, coupon interest, and maturities - than to reallocate current asset holdings. ${ }^{9}$ As a result, the simple stock adjustment models (2) and (3) are inadequate in failing to distinguish clearly between new cash flows and previous-period wealth (including capital gains and net of repayments).

Figure 1 illustrates explicitly this overrestrictiveness of portfolio adjustment models (2) and (3) by representing portfolio adjustment model (3) for the case of an investor whose portfolio consists of two assets only, holdings of which are indicated by distances from the origin in the twodimensional diagram. For fixed asset prices $P_{1}$ and $P_{2}$ for assets $A_{1}$ and $A_{2}$, respectively, the straight line from $\left[0,\left(W_{t-1} / P_{2}\right)\right]$ to $\left[\left(W_{t-1} / P_{1}\right), 0\right]$ represents the investor's wealth constraint in time period $(t-1)$, and the parallel line from $\left[0,\left(W_{t} / P_{2}\right)\right]$ to $\left[\left(W_{t} / P_{1}\right), 0\right]$ represents the wealth constraint after an increment $\Delta W_{t}>0$. Point $Y_{t-1}$ indicates the investor's previous period asset holdings $\left(A_{1, t-1}, A_{2, t-1}\right)$, and point $Y_{t}$ indicates the holdings $\left(A_{1 t}, A_{2 t}\right)$ which would result from no reallocation of the existing asset holdings and allocation of the wealth increment $\Delta W_{t}$ in proportion to the actual holdings at time period $(t-1)$. Point $Z_{t}^{*}$ indicates the desired equilibrium holdings $\left(A_{1 t}^{*}, A_{2 t}^{*}\right)$. Point $Z_{t}$ indicates the actual holdings $\left(A_{1 t}, A_{2 t}\right)$ which result from portfolio adjustment model (3).

${ }^{8}$ In recent years, quoted bid/asked spreads in the professional corporate bond market have fallen to fairly low levels for a wide selection of securities as trading volume in these securities has grown. Nevertheless, since the market as a whole has remained quite thin, institutional investors are conscious of the extent to which sizable transactions that they may attempt can cause both bid and asked quotations to shift in the direction representing a market deterioration from their current point of view. Hence quoted bid/asked spreads understate true direct pecuniary transactions costs. With respect to private placements, trading liquidity is limited but is nevertheless often greater than Shapiro and Wolf (1972) implied.

${ }^{9}$ Duesenberry (1963) has made this point, as have a number of subsequent writers. 


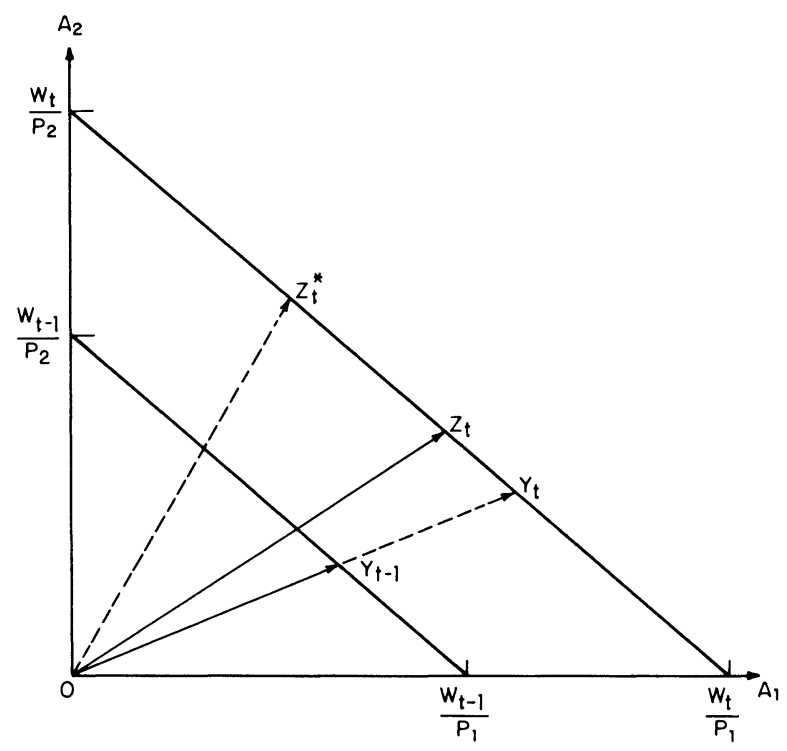

FIG. 1.-Portfolio adjustment model (3), two-asset case

The necessary and sufficient conditions for points $Z_{t}$ and $Z_{t}^{*}$ in figure 1 to be identical are $\theta_{11}-\theta_{12}=\theta_{22}-\theta_{21}=1$. In the absence of such a complete adjustment model, $Z_{t}$ and $Z_{t}^{*}$ are not identical, and the model's symmetrical adjustment factor, applicable to both assets, is indicated by the ratio of the lengths of line segments $Y_{t} Z_{t}$ and $Y_{t} Z_{t}^{*}$,

$$
\frac{Y_{t} Z_{t}}{Y_{t} Z_{t}^{*}}=\frac{\alpha_{1 t}-\alpha_{1, t-1}}{\alpha_{1 t}^{*}-\alpha_{1, t-1}}=\frac{\alpha_{2 t}-\alpha_{2, t-1}}{\alpha_{2 t}^{*}-\alpha_{2, t-1}}=\theta_{11}+\theta_{22}-\bar{\theta},
$$

which is independent of the wealth increment $\Delta W_{t}{ }^{10}$

Hence the standard stock adjustment model-even in the full form including "cross-discrepancies" 11 -is too restrictive in that it does not

${ }^{10}$ As defined for equation (3), $\bar{\theta}$ is the identical sum of each column in the matrix of adjustment coefficients. The symmetry of the two-asset case, by which $\left(\alpha_{1 t}-\alpha_{1, t-1}\right) /$ $\left(\alpha_{1 t}^{*}-\alpha_{1, t-1}\right)=\left(\alpha_{2 t}-\alpha_{2, t-1}\right) /\left(\alpha_{2 t}^{*}-\alpha_{2, t-1}\right)$, does not hold in the general case; for three or more assets, the $\left(\alpha_{i t}-\alpha_{i, t-1}\right) /\left(\alpha_{i t}^{*}-\alpha_{i, t-1}\right)$ are not necessarily equal but are still independent of $\Delta W_{t}$. The purpose of figure 1 is to illustrate this independence of the $\left(\alpha_{i t}-\alpha_{i, t-1}\right) /\left(\alpha_{i t}^{*}-\alpha_{i, t-1}\right)$ and $\Delta W_{t}$ in the stock adjustment model. The graphical convenience of two dimensions is the only reason for using a two-asset model in the figure.

${ }^{11}$ Brainard and Tobin (1968) have emphasized the importance of the dependence of the adjustment of any asset holding $\Delta A_{i t}$ on the discrepancy $\left(A_{k t}^{*}-A_{k, t-1}\right)$ for other assets $k \neq i$. An implication of this point for model (2) is that, if $\theta_{i k}=0$ for $k \neq i$, so that the model is equivalent to

$$
\Delta A_{i t}=\theta_{i i}\left(A_{i t}^{*}-A_{i, t-1}\right), \quad i=1, \ldots, N,
$$

then $\theta_{i i}=1$ for all $i$, and the model requires full adjustment of each asset holding $A_{i, t-1}$ to the desired holding $A_{i t}^{*}$, so that $A_{i t}=A_{i t}^{*}$ for all $i$. The analogous implication of this 
reflect the greater adjustability of new cash flows in comparison with existing asset holdings. In the context of a disaggregated (by investor) model, transactions costs should render each investor category's asset demands dependent in the short run on the investable cash flow of that particular category of investors.

In principle, the ideal way to represent the effect on portfolio behavior of the easier (less costly) allocation of cash flow would be a model incorporating some set of discontinuities or switch-over points. If $\left(A_{i t}^{*}-A_{i, t-1}\right) \geq 0$ for all $i$, then no selling of previously held assets is necessary. If $\left(A_{i t}^{*}-A_{i, t-1}\right)<0$ for some $i$, then $\Delta W_{t}$ is insufficient to meet all desired purchases; $\Delta W_{t}$ should be applied only to purchasing assets $A_{i}$ for which $\left(A_{i t}^{*}-A_{i, t-1}\right)>0$. The discontinuous aspects of such a model would render it empirically intractable, however, and the use of data at any level but that of the individual portfolio would be inappropriate in this context.

Perhaps the simplest way of incorporating explicit flow effects on portfolio adjustments without introducing such discontinuities is to separate the reallocation of existing holdings from the allocation of the new cash flow, applying fixed coefficients to the flow itself: ${ }^{12}$

$$
\Delta A_{i t}=\sum_{k}^{N} \theta_{i k}\left(\alpha_{k t}^{*} \cdot W_{t-1}-A_{k, t-1}\right)+\delta_{i} \Delta W_{t}, \quad i=1, \ldots, N,
$$

point for model (3) is that, if $\theta_{i k}=0$ for $k \neq i$, so that the model is equivalent to

$$
\Delta \alpha_{i t}=\theta_{i i}\left(\alpha_{i t}^{*}-\alpha_{i, t-1}\right), \quad i=1, \ldots, N,
$$

then the $\theta_{i i}$ are identical for all $i$, and the model requires equal fractional adjustment of each asset proportion $\alpha_{i, t-1}$ toward the desired proportion $\alpha_{i t}^{*}$.

12 Model (5) is similar, but not identical, to Brainard and Tobin's (1968) rendering of model (2). Since $A_{k t}^{*}=\alpha_{k t}^{*} W_{t}$ for all $k$, the Brainard-Tobin equation (p. 107) is analogous to

$$
\Delta A_{i}^{*}=\sum_{k}^{N} \theta_{i k}\left(A_{k t}^{*}-A_{k, t-1}\right)+\delta_{i} \Delta W_{t}, \quad i=1, \ldots, N .
$$

As Smith (1975) has pointed out, model (5') "overdescribes" the portfolio disequilibrium, since $\sum_{k}\left(A_{k t}^{*}-A_{k, t-1}\right)=\Delta W_{t}$. To implement the Brainard-Tobin model, therefore, it is necessary either to eliminate the term in $\Delta W_{t}$, thereby rendering ( $\left.5^{\prime}\right)$ identical to (2), or to delete the term in $\left(A_{k t}^{*}-A_{k, t-1}\right)$ for some arbitrary $k$, as Brainard and Tobin did implicitly in their table 3 (p. 108). (A further difference between either [5] or [5'] and the Brainard-Tobin model is not fundamental: Brainard and Tobin further divided $\Delta W_{t}$ into capital gains [on equities] and all other wealth increments, i.e., they replaced $\left[\delta_{i} \Delta W_{t}\right]$ by $\left[\varepsilon_{i} \Delta W_{1 t}+\eta_{i} \Delta W_{2 t}\right]$, where $\Delta W_{1}$ is capital gains and $\Delta W_{2}$ is the sum of all other elements of the total wealth increment $\Delta W$. For the capital gains term $\Delta W_{1 t}$, they assumed that the $\varepsilon_{i}$ coefficient in the equity equation has value unity and all other $\varepsilon_{i}$ have value zero. For the other wealth flow term $\Delta W_{2 t}$, they assumed that the $\eta_{i}$ coefficient in the deposit equation has value unity and all other $\eta_{i}$ have value zero.) Some researchers have based empirical work on model (5); see, for example, Kopcke (1973). For empirical work relying specifically on Brainard and Tobin (1968), see, for example, Smith and Brainard (1974). For an alternative viewpoint on empirical implementation of the Brainard-Tobin model, see Ando and Modigliani (1975). 
where the $\delta_{i}$ are fixed coefficients such that $0 \leq \delta_{i} \leq 1$ for all $i$ and $\sum_{i} \delta_{i}=1$, and the constraint on the $\theta_{i k}$ is $\sum_{i} \theta_{i k}=\bar{\theta}$ for all $k$, as in model (3). The first term on the right-hand side of model (5) represents the reallocation of the existing wealth $W_{t-1}$, while the second term represents the allocation of the flow of new wealth $\Delta W_{t}$.

Although model (5) may represent some improvement over models (2) and (3), in that the adjustments $\left(\alpha_{i t}-\alpha_{i, t-1}\right) /\left(\alpha_{i t}^{*}-\alpha_{i, t-1}\right)$ (analogous to ratio $\left[Y_{t} Z_{t}\right] /\left[Y_{t} Z_{t}^{*}\right]$ in fig. 1) depend explicitly upon $\Delta W_{t}$, the fixed coefficients $\delta_{i}$ render it inadequate for most investors, except for extremely short time periods. In particular, assuming that investors always allocate new cash flows in fixed proportions, regardless of market yields and other variables relevant to portfolio behavior, is in some sense more restrictive than assuming no distinction at all between allocation of the new cash flow and reallocation of existing holdings. Furthermore, only by chance will a growing portfolio ever reach equilibrium if it is invested according to model (5), even if the desired proportional allocations $\alpha_{k t}^{*}$ are constant.

A compromise between these two restrictive approaches is a model which allocates the flow of new investable funds according to whatever proportions portfolio selection model (1) indicates are the desired equilibrium proportions for the portfolio as a whole - that is, a model which, away from equilibrium, uses equilibrium total proportions to allocate at the margin. The "optimal marginal adjustment" model indicated by this specification is an analogue of model (5) which replaces that model's invariant flow allocation coefficient $\delta_{i}$ for each asset by the corresponding current desired proportion $\alpha_{i t}^{*}:{ }^{13}$

$\Delta A_{i t}=\sum_{k}^{N} \theta_{i k}\left(\alpha_{k t}^{*} \cdot W_{t-1}-A_{k, t-1}\right)+\alpha_{i t}^{*} \Delta W_{t}, \quad i=1, \ldots, N$.

Such a model seems especially appropriate for investors participating in private securities markets, in which some level of fairly continuous activity maintains the flow of information about new investment opportunities. Institutional investors such as insurance companies and pension funds, for example - which participate not only in the market for publicly offered debt issues but also in the markets for privately placed corporate debt securities, commercial mortgages, and other forms of negotiated

${ }^{13}$ Modigliani (1972) used a model which is similar to the optimal marginal adjustment model (6) but which allocates the current-period flow according to the observed previousperiod stock allocation $\alpha_{i, t-1}$. The optimal marginal adjustment model allocates the flow according to the desired equilibrium stock allocation $\alpha_{i t}^{*}$. Although the two models appear similar, the rationale is very different. The optimal marginal adjustment model is a description especially relevant for institutional investors operating in markets with transactions (including information) costs. Modigliani's model, which he applied in particular to household demand for savings deposits, explicitly postulates a short-run desired allocation which differs from the (long-run) equilibrium desired allocation. 


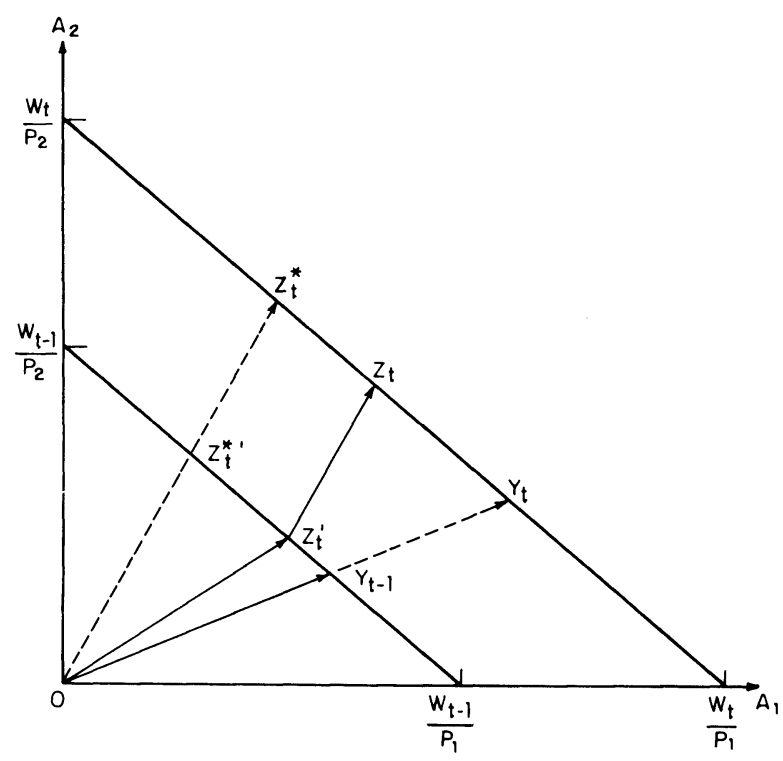

Fig. 2.-Portfolio adjustment model (6), two-asset case

loans-are typically reluctant to undertake sharp negative swings in their new purchasing activities for long periods of time. The optimal marginal adjustment model also serves to approximate this type of smoothed behavior.

Figure 2 illustrates the advantage of the optimal marginal adjustment model (6) in the two-asset case analogous to that depicted in figure 1. Points $Y_{t-1}, Y_{t}$, and $Z_{t}^{*}$ are as in figure 1 . The first term on the right-hand side of model (6) represents the reallocation of the existing wealth $W_{t-1} \cdot{ }^{14}$ Figure 2 depicts this reallocation as a move along the $W_{t-1}$ wealth constraint from point $Y_{t-1}$ toward point $Z_{t}^{* \prime}$; point $Z_{t}^{* \prime}$ is the intersection of the $W_{t-1}$ wealth constraint and the ray from the origin which passes through point $Z_{t}^{*}$. Except for the special case of full adjustment $\left(\theta_{i i}=1\right.$ for all $i$, and $\theta_{i k}=0$ for $k \neq i$ ), this reallocation process leads not to point $Z_{t}^{* \prime}$ itself but rather to point $Z_{t}^{\prime}$ which lies between $Z_{t}^{* \prime}$ and $Y_{t-1}$ on the $W_{t-1}$ wealth constraint. The portfolio adjustment model's $\theta_{i k}$ coefficients determine the adjustment ratio $\left(Y_{t-1} Z_{t}^{\prime}\right) /\left(Y_{t-1} Z_{t}^{* \prime}\right)$. If wealth is constant, the movement to point $Z_{t}^{\prime}$ is the only component of the portfolio adjustment, and model (6) reduces to model (3).

${ }^{14}$ The $W_{t-1}$ variable in model (6) includes capital gains but excludes repayments, which become part of the gross cash flow variable $\Delta W_{t}$. For simplicity, the example shown in figure 2 assumes no repayments. As in figure 1, it also abstracts from capital gains by assuming constant asset prices. 
The second term on the right-hand side of model (6) represents the allocation of the wealth increment $\Delta W_{t}$ according to the current desired proportions $\alpha_{i t}^{*}$. Figure 2 depicts this allocation as a movement from point $Z_{t}^{\prime}$ on the $W_{t-1}$ wealth constraint to point $Z_{t}$ on the $W_{t}$ wealth constraint, along a line parallel to the ray from the origin which passes through point $Z_{t}^{*}$. Point $Z_{t}$ indicates the new holdings $\left(A_{1 t}, A_{2 t}\right)$ which result from portfolio adjustment model (6). In contrast to model (3) as illustrated in figure 1, figure 2 shows that, for given $W_{t-1}$, the symmetrical adjustment ratio $\left(Y_{t} Z_{t}\right) /\left(Y_{t} Z_{t}^{*}\right)=\left(\alpha_{1 t}-\alpha_{1, t-1}\right) /\left(\alpha_{1 t}^{*}-\alpha_{1, t-1}\right)=$ $\left(\alpha_{2 t}-\alpha_{2, t-1}\right) /\left(\alpha_{2 t}^{*}-\alpha_{2, t-1}\right)$ in model (6) varies positively with the flow $\Delta W_{t}{ }^{15}$

Hence the optimal marginal adjustment model, without sacrificing either tractability or suitability for empirical application to aggregative data, serves the intended purpose of relaxing the restrictiveness of the standard stock adjustment model with respect to investors' allocation of their cash flows. The model therefore leads to asset demand equations in which investable cash flow variables matter for short-run allocations. In particular, the greater the new cash flow, the faster the portfolio's overall adjustment toward equilibrium allocation. Section II shows how a structural model relying on asset demand equations of this form in turn renders flow variables determinants of the short-run variation of asset yields.

\section{The Market-clearing Structural Model}

Economists' models of the determination of long-term interest rates have usually adopted a term-structure approach, according to which the value of a representative long-term rate of nominal interest depends upon the value of a representative short-term rate of nominal interest, with the spread between the two rates determined by some set of economic factors which influence the behavior of borrowers or lenders or both. Among the familiar factors which various writers have suggested including as determinants of this spread are the expected future path of the short-term rate of interest (usually represented by some distributed lag on past values of the short-term rate; see, e.g., Meiselman [1962], Malkiel [1966], and Modigliani and Sutch [1966]), a premium reflecting the differential liquidity of short- and long-term debt instruments (Hicks [1939]; Kessel [1971]), expected future price inflation in product markets (usually represented by some distributed lag on past values of a chosen price inflation index; Modigliani and Shiller [1973]), and an index of current central

\footnotetext{
15 As in figure 1, the symmetry of adjustments is a particular result due to the twoasset model. The dependence of the $\left(\alpha_{i t}-\alpha_{i, t-1}\right) /\left(\alpha_{i t}^{*}-\alpha_{i, t-1}\right)$ ratios on $\Delta W_{t}$ in model (6) holds for any number of assets. See n. 10 above.
} 
bank monetary policy beyond interest rates themselves (e.g., the recent rate of growth of some monetary or reserve aggregate). ${ }^{16}$

The prevailing empirical methodology of the term-structure approach has been a model consisting of a single unrestricted reduced-form equation with the nominal long-term interest rate as the dependent variable. The use of this methodology implies an acceptance of two key assumptions, at least as close approximations. First, it assumes that not only the shortterm interest rate but also the determinants of the long/short spread are exogenous with respect to the actions of participants in the market for long-term debt securities. ${ }^{17}$ Second-and more important, from the standpoint of this paper - it assumes that the way in which participants in the market for long-term securities, either individually or in the aggregate, adjust their actions in that market in response to any or all of the determinants of portfolio behavior does not matter for the ex post outcome for the long-term interest rate. In particular, this second assumption implies that the quantities of long-term securities bought or sold, either by individual transactors or for the market in aggregate, do not influence the ex post outcome for the long-term interest rate. A few writers have suggested relaxing this second assumption somewhat by incorporating exogenous supplies of long-term securities as a further determinant of the long/short spread, but they have done so within the familiar unrestricted reduced-form equation methodology of the termstructure approach. ${ }^{18}$

The structural model of long-term interest rate determination, as applied in this paper, drops the second of these two assumptions and specifies equations directly representing the portfolio behavior of bond market participants. The addition of a market-clearing constraint, equating the sum of the demands for long-term debt securities to the sum of the supplies of long-term debt securities, enables the structural model to determine the long-term interest rate (i.e., the own yield) which appears as a right-hand-side variable in each structural demand or supply equation. ${ }^{19}$ The resulting implicit expression for the long-term interest

\footnotetext{
${ }^{16}$ See, for example, Feldstein and Eckstein (1970). Their work is within the usual approach empirically, in that they estimated an unrestricted equation with the long-term interest rate as the dependent variable. Conceptually, however, they rejected the termstructure approach, omitting the short-term yield altogether and interpreting the estimated equation as an inverted form of money-demand function.

${ }^{17}$ See Feldstein and Chamberlain (1973) for an unusually careful treatment of this issue, within the context of the single-equation reduced-form approach.

${ }^{18}$ Feldstein and Eckstein (1970) used the stock supply of U.S. government securities in this way. Fair and Malkiel (1971) used "visible" flow supplies of new corporate bonds in reduced-form equations for spreads between yields on different types of long-term securities; the determination of long-term yield spreads in this way is a corollary to the determination of the long/short spread in the term-structure approach.

${ }^{19}$ Silber (1970) and Hendershott and Lemmon (1973) have also applied this approach. Bosworth and Duesenberry (1973) used this approach conceptually, but not in their
} 
rate is a kind of reduced-form equation (it may be nonlinear) which is restricted by the associated structural supply and demand equations.

Hence the key methodological difference between the structural approach and the familiar term-structure approach to modeling longterm interest rate determination is essentially equivalent to the distinction between restricted and unrestricted estimation. The principal advantage of the structural approach is its ability to use the underlying theory of portfolio behavior to constrain the implied equation for the long-term interest rate, which in turn facilitates directly testing hypotheses about portfolio behavior. The structural approach imposes upon the researcher the discipline of having to acknowledge explicitly that any factor hypothesized to influence the bond yield can do so only by influencing some issuer's supply of bonds or some investor's demand for bonds (or both). To the extent that less-than-infinite elasticities of substitution create "preferred habitats" which render quantity variables relevant, for example, or to the extent that less-than-infinite adjustment speeds render quantity flow variables relevant as well as quantity stock variables, in the structural model such factors can influence the determination of the long-term interest rate only by influencing the behavior of borrowers and lenders.

Since the long-term interest rate is clearly a jointly determined variable in this model, along with the demand and supply variables, it is necessary to use estimation techniques which avoid inconsistencies to which ordinary least-squares procedures would be subject because of the nature of the model's simultaneity. The empirical work described in Section IV below focuses entirely on the investor side of the corporate bond market, while Friedman (1976) develops an analogous treatment of bond issuers. The simulation results presented in Section $\mathrm{V}$ are derived from a simulation of the bond demand model alone, with bond supply taken as exogenous, and also from a separate simulation of the combined model of bond demand and bond supply.

The particular long-term interest rate to be determined in this model is the observed new-issue yield on long-term bonds issued by utility companies rated Aa by Moody's Investors Service, Inc. Aa-rated utility bonds provide the greatest continuity, in terms of the frequency of new issues; they are also most representative of new-issue activity in the U.S. corporate bond market. Previous studies of long-term interest rate determination using the term-structure approach have relied on indexes of yields either on new issues or seasoned issues, but the new-issue yield is likely to be superior for several reasons. First, trading in the corporate bond market involves either new issues or recent issues to a far greater

empirical work; instead, for each asset, they typically dropped one sector's demand equation and estimated an unrestricted equation with the asset's yield as the dependent variable and the omitted sector's demand as an independent variable. 
extent than seasoned issues, and quoted price movements among seasoned issues are often just a reflection of what is happening in the new-issue market. Second, because of thin trading markets, problems of measurement are considerably smaller for new issues than for seasoned issues. Third, Modigliani and Shiller (1974) have shown that differences in coupon rates between current new issues and the issues used in constructing seasoned yield indexes introduce a form of bias into the seasoned yield index itself.

The structural equations presented in Section IV represent investors' demands for long-term corporate bonds. These equations follow the optimal marginal adjustment model of portfolio behavior developed in Section I in their treatment of financial flow variables. In addition, by disaggregating demand according to six major categories of corporate bond investors, these equations permit the various investing sectors' cash flows to exert differential effects on the determination of the long-term yield. The six categories of investors treated as endogenous in this model are (1) life insurance companies, (2) other insurance companies, (3) private pension funds, (4) state and local government retirement funds, (5) mutual savings banks, and (6) households. ${ }^{20}$ As of the end of 1974, as table 1 shows, these investors held approximately 94 percent of all outstanding long-term corporate bonds issued in the United States. The model treats as exogenous all other investors' demands for long-term corporate bonds.

The portfolio behavior model developed in Section I deals with a single investor's, or investor category's, demands for all assets (or liabilities) in the markets for which the investor participates. By contrast, the structural model used in this paper focuses on one asset (long-term corporate bonds) and includes behavioral equations describing the demand for that single asset by each major category of investors participating in that particular market. Hence each of the six structural demand equations is implicitly an element of a set of demand equations which satisfy the "adding-up" constraints specified in Section I.

As Ladenson (1971) and Smith (1975) have shown, however, it is not necessary to use constrained estimation techniques to guarantee that the parameter estimates of the full set of demand equations for any investor category satisfy the "adding-up" constraints, and so there is no inconsistency involved in estimating only one demand equation, rather than the entire set, for each category of investors. In principle, however, a full model including all investors and all markets (i.e., all assets) would be preferable for two reasons. First, it would render all yields-not just the own-yield on the one asset under consideration-jointly determined

${ }^{20}$ The household sector consists primarily of individuals but also includes nonprofit organizations and bank-managed personal trusts. 
TABLE 1

Distribution of U.S. Corporate Bond Holdings

\begin{tabular}{|c|c|c|}
\hline Bonds Held By: & $\begin{array}{c}\text { Amount } \\
\text { (\$ Billions) }\end{array}$ & Percentage \\
\hline Life insurance companies* & 97.9 & 34.1 \\
\hline State and local government retirement funds* & 57.8 & 20.1 \\
\hline Households* ..... & 54.5 & 19.0 \\
\hline Private pension funds* & 34.5 & 12.0 \\
\hline Mutual savings banks* & 14.1 & 4.9 \\
\hline Other insurance companies* & 11.0 & 3.8 \\
\hline Commercial banks ....... & 7.3 & 2.5 \\
\hline Mutual funds......... & 3.8 & 1.3 \\
\hline Foreign investors $\ldots \ldots \ldots \ldots \ldots$ & 3.5 & 1.2 \\
\hline Brokers and dealers ... & 2.7 & 0.9 \\
\hline Total. . & 287.1 & 100.0 \\
\hline
\end{tabular}

Nore.-Detail may not add to total because of rounding; all data are at par value except foreign; groups marked by asterisk are endogenous in model.

variables. Second, it would permit the researcher to adopt the philosophy as well as the mechanics of Brainard and Tobin (1968) by examining the implications for other asset demand equations of the presence of a given variable in any one asset demand equation. Nevertheless, the construction of such a full model lies beyond the scope of this paper. ${ }^{21}$

\section{Estimation Procedures and Data}

Before proceeding to the empirical results in Section IV, it is worthwhile to comment briefly on both the estimation procedures and the data used.

\section{Estimation Procedures}

The long-term corporate bond demand equation estimated for each of the six categories of investors combines the linear homogeneous selection model and the optimal marginal adjustment model, as developed in Section I. ${ }^{2}$ To see the implications of the combination of selection model

${ }^{21}$ For examples of efforts toward building such a full model, see Bosworth and Duesenberry (1973), Hendershott and Lemmon (1973), Smith and Brainard (1974), Ando and Klein (1975), and Fromm and Sinai (1975).

22 Especially for those categories of investors which are not heavily involved in private placement markets, preliminary experiments also used an alternative portfolio adjustment model of the form

$$
\Delta \alpha_{i t}=\sum_{k}^{N}\left(\theta_{i k}+\phi_{i k} \frac{\Delta W_{t}}{W_{t-1}}\right)\left(\alpha_{k t}^{*}-\alpha_{k, t-1}\right), \quad i=1, \ldots, N,
$$

where the $\phi_{i k}$ coefficients satisfy the same constraint which applies to the $\theta_{i k}$ coefficients in model (3). This adjustment model, which also allows the flow $\Delta W_{t}$ to influence the portfolio allocation but does so in a more general way than model (6), uniformly led to less satisfactory empirical results than those obtained using the optimal marginal adjustment model (6). 
(1) and adjustment model (6) into the overall model of portfolio behavior, it is useful to expand the resulting equation, grouping the variables in the following way:

$$
\begin{aligned}
\Delta A_{i t}= & \pi_{i} \cdot \Delta W_{t}+\left[\sum_{k}\left(\pi_{k} \cdot \theta_{i k}\right)\right] \cdot W_{t-1} \\
& +\beta_{i i} \cdot r_{i t} \cdot \Delta W_{t}+\left[\sum_{k}\left(\beta_{k i} \cdot \theta_{i k}\right)\right] \cdot r_{i t} \cdot W_{t-1} \\
& +\sum_{k \neq i}\left\{\beta_{i k} \cdot r_{k t} \cdot \Delta W_{t}+\left[\sum_{j}\left(\beta_{j k} \cdot \theta_{i j}\right)\right] \cdot r_{k t} \cdot W_{t-1}\right\} \\
& +\sum_{h}\left\{\gamma_{i h} \cdot X_{h} \cdot \Delta W_{t}+\left[\sum_{k}\left(\gamma_{k h} \cdot \theta_{i k}\right)\right] \cdot X_{h} \cdot W_{t-1}\right\} \\
& -\theta_{i i} \cdot A_{i, t-1}-\sum_{k \neq i}\left(\theta_{i k} \cdot A_{k, t-1}\right) .
\end{aligned}
$$

The flow $\Delta W_{t}$ and lagged wealth stock $W_{t-1}$ enter equation (7) linearly, but in neither case is the coefficient sign known a priori; $\pi_{i}$ is simply the constant term corresponding to asset $A_{i}$ in selection model (1), and $\pi_{k}$, $k \neq i$, are the analogous constant terms in the selection model equations for other assets $A_{k}, k \neq i .^{23}$ The own yield $r_{i t}$ enters equation (7) twice, in nonlinear form both times. The coefficient of the $\left(r_{i t} \cdot \Delta W_{t}\right)$ term is $\beta_{i i}>0$, but the coefficient of the $\left(r_{i t} \cdot W_{t-1}\right)$ term is a sum of coefficients which is of unknown sign a priori. ${ }^{24}$ The yields on alternative assets $r_{k t}, k \neq i$, also enter equation (7) twice, in nonlinear form both times. Once again, the coefficient of each $\left(r_{k t} \cdot \Delta W_{t}\right)$ term, for $k \neq i$, is $\beta_{i k}<0$, but the coefficient of each $\left(r_{k t} \cdot W_{t-1}\right)$ term is a sum of coefficients which is of unknown sign a priori. Each nonyield variable $X_{h}$ also enters in a precisely analogous way. Finally, the lagged own stock $A_{i, t-1}$ enters linearly with coefficient $-\theta_{i i}<0$, and the lagged stocks of competing assets $A_{k, t-1}, k \neq i$, enter linearly with coefficients of unknown sign. ${ }^{25}$

23 This feature of the model is in sharp contrast to the work of Bosworth and Duesenberry (1973) and Hendershott and Lemmon (1973) who, without explicitly developing the underlying portfolio adjustment model, emphasized the linear appearance of cash flow variables. A consequence of the optimal marginal adjustment model is that it is the nonlinear terms, with cash flow multiplied by another variable, which matter. The cash flow or lagged wealth stock in linear form could just as well have zero coefficient, as many do in the estimation results presented in Section IV.

${ }^{24}$ The indeterminancy of $\sum_{k}\left(\beta_{k i} \cdot \theta_{i k}\right)$ is due to the unknown signs of $\theta_{i k}, k \neq i$, since $\beta_{i i}>0$ and presumably $\beta_{i k}<0, k \neq i$. Although an intuitive guess is $\theta_{i k}<0, k \neq i$ (which would then render the sum unambiguously positive), there is no reason to presume $\theta_{i k}<0, k \neq i$, since $\alpha_{i t}^{*} \lessgtr \alpha_{i, t-1}$ itself implies $\alpha_{k t}^{*} \gtrless \alpha_{k, t-1}$ for at least some $k \neq i$. Hence the adjustment coefficients $\theta_{i k}, k \neq i$, are of unknown sign. I am grateful to William Brainard, Gary Smith, and James Tobin for an illuminating discussion of this point.

${ }^{25}$ See $n .24$ above. 
TABLE 2

Principal Assets for Six Investor Categories

\begin{tabular}{|c|c|}
\hline Category and Assets & $\begin{array}{l}\text { Percentage of Total } \\
\text { Financial Assets }\end{array}$ \\
\hline \multicolumn{2}{|l|}{ Life insurance companies: } \\
\hline Corporate bonds $\ldots \ldots$ & 38.3 \\
\hline Commercial mortgages .... & 25.0 \\
\hline Equities..$\ldots \ldots \ldots \ldots$ & 8.7 \\
\hline Residential mortgages & 8.8 \\
\hline Subtotal .......... & $\overline{80.8}$ \\
\hline \multicolumn{2}{|l|}{ Other insurance companies: } \\
\hline Corporate bonds . ........ & 16.1 \\
\hline Municipal bonds $\ldots \ldots \ldots \ldots \ldots \ldots \ldots \ldots \ldots \ldots \ldots \ldots$ & 47.1 \\
\hline 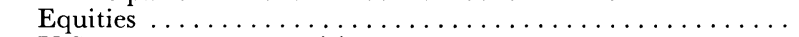 & 18.3 \\
\hline U.S. government securities $\ldots \ldots \ldots \ldots \ldots$. & 5.4 \\
\hline Subtotal .............. & $\overline{86.9}$ \\
\hline \multicolumn{2}{|l|}{ Private pension funds: } \\
\hline Corporate bonds ... & 29.1 \\
\hline Equities $\ldots \ldots \ldots \ldots \ldots \ldots$ & 55.6 \\
\hline U.S. government securities & 4.6 \\
\hline 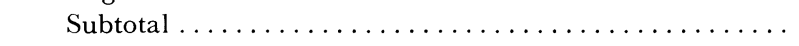 & $\overline{89.3}$ \\
\hline \multicolumn{2}{|l|}{ State and local government retirement funds: } \\
\hline 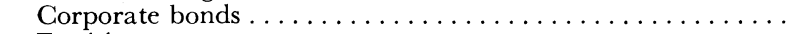 & 61.6 \\
\hline Equities $\ldots \ldots \ldots \ldots \ldots \ldots \ldots \ldots \ldots \ldots \ldots \ldots$ & 23.5 \\
\hline U.S. government securities . & 5.6 \\
\hline 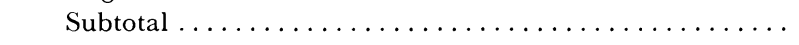 & $\overline{90.7}$ \\
\hline \multicolumn{2}{|l|}{ Mutual savings banks: } \\
\hline Corporate bonds . & 12.8 \\
\hline Residential mortgages ... & 40.7 \\
\hline Commercial mortgages $\ldots \ldots \ldots \ldots$ & 27.7 \\
\hline U.S. government securities ... & 6.3 \\
\hline Subtotal $\ldots \ldots \ldots \ldots \ldots \ldots \ldots \ldots$ & $\overline{87.5}$ \\
\hline \multicolumn{2}{|l|}{ Households: } \\
\hline Corporate bonds & 2.5 \\
\hline Liquid assets .. & 45.4 \\
\hline Demand deposits and currency..... & 8.0 \\
\hline Time deposits and savings accounts... & 31.9 \\
\hline U.S. government securities $\ldots \ldots \ldots \ldots \ldots$ & 5.5 \\
\hline Equities & 24.0 \\
\hline Municipal bonds . & 2.8 \\
\hline Subtotal .... & 74.7 \\
\hline
\end{tabular}

Most of the six investor categories examined here hold at least some amounts of a large number of different types of assets. For each category, the procedure used in estimation was to select the few assets which, along with corporate bonds, comprise the major elements in the investors' aggregate portfolios. Table 2 lists such likely asset groups for each of the six investor categories and shows the percentage of the sector's total financial portfolio for which each asset accounted as of year-end 1974. As the discussion in Section I notes, ${ }^{26}$ equation (7) is not identifiable in the 
form including not only $W_{t-1}$ and $A_{i, t-1}$ but also $A_{k, t-1}$ for all $k \neq i$. The procedure used to deal with this problem was to estimate each equation once including $W_{t-1}$ and $A_{i, t-1}$ only (thereby implicitly imposing the constraint that the cross-adjustment coefficients $\theta_{i k}$ are identical for all $k \neq i)$; once including $A_{i, t-1}$ and all $A_{k, t-1}, k \neq i$, but excluding $W_{t-1}$; and then including $W_{t-1}, A_{i, t-1}$ and $A_{k, t-1}$ for only some subset of $k \neq i$. Final selection among these alternative constrained subspecifications depended on goodness of fit and statistical properties. With respect to the yields, the analogous procedure used was to include only some subset of yields $r_{k t}$ on alternative assets $k \neq i$.

As the discussion in Section II emphasizes, it is necessary to use some form of consistent estimation procedure to avoid simultaneity problems due to the joint determination of the own yield on long-term corporate bonds and the demand variables which are the dependent variables in the six separate equations of form (7). As is typically the case in multiequation models, it is impossible to apply the two-stage least-squares method directly because there are too many exogenous variables to permit ordinary least-squares estimation of the system's reduced form, as this method requires. The procedure used here follows Brundy and Jorgenson (1971) in using as instrumental variables not only the leading principal components of the full-system set of exogenous variables but also, on an equation-by-equation basis, the single-equation sets of exogenous variables themselves.

A final issue in estimation procedure is the question of an intercept term. Equation (7) has no such term, but it is probably accurate to consider the portfolio behavior model developed in Section I as a linear approximation to a more complex behavioral pattern, and an intercept may follow from linearization. The procedure used was to include or exclude an intercept in each demand equation according to the $t$-statistic.

\section{Data}

The primary data source for the stock and flow quantities used in this model is the Board of Governors of the Federal Reserve System's flow-offunds accounts (1973, and subsequently). The sample period consists of 56 quarterly observations beginning in 1960:I and ending in 1973:IV.

The bond demand variables- $\Delta A_{i t}$ in equation (7)-are the net purchases of corporate bonds during the quarter, seasonally adjusted, for each of the six investor categories.

The wealth flow variables - $\Delta W_{t}$ in equation (7) - are the net acquisitions of financial assets, seasonally adjusted, for four investor categories: non-life insurance companies, private pension funds, state and local government retirement funds, and mutual savings banks. For life insurance companies, $\Delta W_{t}$ is the net acquisition of financial assets, 
seasonally adjusted, less net policy loans; the reason for the subtraction is that policy loans are exogenous to the portfolio behavior of life insurance companies, which have available for investment only that portion of their cash flow which is left after policy loans. For households, $\Delta W_{t}$ is the net acquisition of financial assets, seasonally adjusted, plus the capital gains portions of pension fund and life insurance reserves.

Since the "net acquisitions of financial assets" concept excludes capital gains, defining the six $\Delta W_{t}$ variables on this basis effectively imposes on the portfolio model a part of the Brainard-Tobin assumption discussed in connection with model (5) in Section I. In particular, it assumes that investors do not respond within the current quarter to shifts of their portfolios due to capital gains. ${ }^{27}$ It is also important to point out that the "net acquisitions of financial assets" concept differs from the $\Delta W_{t}$ flow variable discussed in Section I precisely because it is "net." As the discussion in Section I explains, the relevant flow concept should include repayments. Nevertheless, gross cash flow data are simply unavailable for most categories of investors.

The asset stock variables $A_{k t}$, for all six investor categories, are constructed by decrementing backward from the end-of-year stocks for 1973, using seasonally adjusted quarterly flows. ${ }^{28}$ For those assets for which the flow-of-funds data incorporate market valuation changes, however, the procedure used was to separate the total quarterly flows into net purchases and market valuation components and to use the latter without seasonal adjustment. ${ }^{29}$ The total wealth variables $W_{t}$ are constructed analogously to the asset stock variables for all six sectors.

\section{Estimation Results}

The equations listed below are the results of estimating equation (7) for each of the six major categories of corporate bond investors. The dependent variable is in each case denominated in millions of dollars. The numbers in parentheses are ratios of estimated values to standard errors for each coefficient; because of the estimation procedure used, these ratios are asymptotically distributed as $t$-statistics but are not necessarily distributed as $t$-statistics in small samples. The $\bar{R}^{2}$ is the coefficient of determination adjusted for degrees of freedom, SE is the standard error of estimate, and D-W is the Durbin-Watson statistic. The variable symbols

${ }^{27}$ See nn. 12 and 14; see also n. 29 below.

28 The object of this procedure is to generate series of seasonally adjusted end-ofquarter stocks without any gaps or inconsistencies due to splicing of data series. The Federal Reserve System does not construct such series.

${ }^{29}$ In principle the data should reflect market valuation adjustments for all assets. The flow-of-funds series used here incorporate such adjustments only for equities and for corporate bonds issued by foreigners. 
listed below are consistent for all six equations, with letter superscripts indicating distinctions among corresponding variables for different investor categories. An asterisk superscript indicates terms for which the equation is estimated using fitted values of the variable from the first stage of the instrumental variables procedure. ${ }^{30}$

$C B=$ holdings of long-term corporate bonds;

$C M=$ holdings of commercial mortgages;

$E Q=$ holdings of equities;

$L A=$ holdings of liquid assets;

$M B=$ holdings of municipal bonds;

$R M=$ holdings of residential mortgages;

$U S=$ holdings of federal government securities;

$r_{C B}=$ corporate bond yield (Moody's Aa new utility issues);

$r_{C M}=$ commercial mortgage yield (ALIA series);

$r_{C P}=$ commercial paper yield (prime 4-6-month paper);

$r_{E Q}=$ equity yield (Standard and Poor's earnings/price ratio);

$r_{M B}=$ municipal bond yield (Moody's Aaa);

$r_{R M}=$ residential mortgage. yield (new FHA insured loans);

$r_{T B}=$ Treasury bill yield (3-month bills);

$X_{1}=$ lagged one-period percentage change of common stock prices (Standard and Poor's index);

$X_{2}=$ four-quarter moving average of $X_{1}$;

$X_{3}=$ lagged eight-quarter moving average percentage change of the consumer price index;

$X_{4}=$ lagged one-period percentage change of $r_{C B}$.

1. Life insurance companies: ${ }^{31}$

$$
\begin{aligned}
& \Delta C B_{t}^{L}=-3354-1.177 \Delta W_{t}^{L}+0.1465 W_{t-1}^{L}+0.4550\left(r_{C B, t} \cdot \Delta W_{t}^{L}\right)^{*} \\
& (-3.9) \quad(-1.7) \quad(3.5) \\
& -0.003119\left(r_{C B, t} \cdot W_{t-1}^{L}\right)^{*}-0.2624 r_{R M, t} \cdot \Delta W_{t}^{L} \\
& (-2.5) \quad(-3.4) \\
& -0.008453 X_{1, t} \cdot \Delta W_{t}^{L}-0.1491 C B_{t-1}^{L}-0.1638 C M_{t-1}^{L} \text {. } \\
& (-2.5) \\
& (-1.9) \\
& (-3.7)
\end{aligned}
$$

${ }^{30}$ Because of the nonlinear way in which yield variables enter the model, as illustrated in equation (7), all such terms are products. The correct instrument to use in each such case, for purposes of deriving consistent estimators, is the first-stage fitted value of the entire product; this procedure is used here.

${ }^{31}$ The life insurance company equation also includes two dummy variables. The first dummy has unit value in 1969:IV and zero value in all other quarters; the flow-of-funds data show negative net purchases of corporate bonds by life insurance companies in this quarter (the only negative value for this series since these data began in 1953). The second dummy has unit value in 1973:I and zero value in all other quarters; the flow-offunds data show an isolated, sharp one-quarter drop in net purchases of corporate bonds in this quarter. 
2. Other insurance companies: ${ }^{32}$

$$
\begin{aligned}
& \Delta C B_{t}^{O}=1696 W T R_{t}^{O}+0.1401\left(r_{C B, t} \cdot \Delta W_{t}^{O}\right)^{*}-0.1318 r_{M B, t} \cdot \Delta W_{t}^{O} \\
& \text { (12.0) } \\
& (-1.8) \\
& -0.02259 X_{2, t} \cdot \Delta W_{t}^{O}-0.1390 C B_{t-1}^{O}-0.06440 U S_{t-1}^{O} \\
& (-7.2) \\
& (-5.3) \\
& (-4.9) \\
& -0.1590 M B_{t-1}^{O} \text {. } \\
& (-15.8)
\end{aligned}
$$
$\bar{R}^{2}=.92$
$\mathrm{SE}=66$
$\mathrm{D}-\mathrm{W}=1.41$

3. Private pension funds: ${ }^{33}$

$$
\begin{aligned}
& \Delta C B_{t}^{P}=0.2407 W_{t-1}^{P}+0.1546\left(r_{C B, t} \cdot \Delta W_{t}^{P}\right) *-0.7157 X_{3, t} \cdot \Delta W_{t}^{P} \\
& (-4.6) \\
& -0.3730 C B_{t-1}^{P}+0.2146 U S_{t-1}^{P}-0.2493 E Q_{t-1}^{P} \text {. } \\
& (-3.5) \\
& \bar{R}^{2}=.67 \\
& \mathrm{SE}=198 \\
& \mathrm{D}-\mathrm{W}=2.32
\end{aligned}
$$

4. State and local government retirement funds:

$$
\begin{aligned}
\Delta C B_{t}^{S}= & -1674+0.1144 W_{t-1}^{S}+0.09882\left(r_{C B, t} \cdot \Delta W_{t}^{S}\right)^{*} \\
& (-2.6) \quad(2.3) \\
- & 0.4678 X_{3, t} \cdot \Delta W_{t}^{S}-0.01467 X_{4, t} \cdot \Delta W_{t}^{S}-0.1450 C B_{t-1}^{S} \\
& (-3.9) \\
+ & 0.1098 U S_{t-1}^{S} . \\
& (2.9)
\end{aligned}
$$

$$
\bar{R}^{2}=.83 \quad \mathrm{SE}=156 \quad \mathrm{D}-\mathrm{W}=1.85
$$

5. Mutual savings banks:

$$
\begin{aligned}
& \Delta C B_{t}^{M}=3819+0.1411\left(r_{C B, t} \cdot \Delta W_{t}^{M}\right)^{*}-0.09626 r_{T B, t} \cdot \Delta W_{t}^{M} \\
& \text { (3.6) (6.5) (-3.2) } \\
& +0.001588 r_{T B, t} \cdot W_{t-1}^{M}-0.002791 r_{C M, t} \cdot W_{t-1}^{M} \\
& (-2.7) \\
& -0.1219 C B_{t-1}^{M}-0.3465 U S_{t-1}^{M}-0.1690 R M_{t-1}^{M} \\
& \begin{array}{lll}
(-3.6) & (-3.6) & (-2.9)
\end{array} \\
& +0.3024 C M_{t-1}^{M} \text {. } \\
& \text { (2.7) } \\
& \bar{R}^{2}=.89 \\
& \mathrm{SE}=134 \\
& \mathrm{D}-\mathrm{W}=2.12
\end{aligned}
$$

32 The variable $W T R^{o}$ is the trend component of the usual wealth variable $W^{o}$. The other insurance company equation also includes a dummy variable with unit value in 1973:II and zero value in all other quarters; the flow-of-funds data show an isolated 
6. Households :

$$
\begin{aligned}
& \Delta C B_{t}^{H}=0.03139\left(r_{C B, t} \cdot \Delta W_{t}^{H}\right)^{*}+0.0003370\left(r_{C B, t} \cdot W_{t-1}^{H}\right)^{*} \\
& -0.02203 r_{E Q, t} \cdot \Delta W_{t}^{H}-0.01628 r_{C P, t} \cdot \Delta W_{t}^{H}-0.1167 C B_{t-1}^{H} \\
& (-1.6) \quad(-3.5) \quad(-7.1) \\
& +0.008501 L A_{t-1}^{H}-0.006204 E Q_{t-1}^{H} \text {. } \\
& \bar{R}^{2}=.79 \\
& \mathrm{SE}=496 \\
& \mathrm{D}-\mathrm{W}=2.34
\end{aligned}
$$

In all six equations the results provide support for the optimal marginal adjustment model of portfolio behavior developed in Sections I and III. First, in all six equations the combined own yield and flow term $\left(r_{C B, t} \cdot \Delta W_{t}\right)$ has a coefficient $\beta_{i i}$ which is significantly different from zero, with the expected positive sign, at the 1 percent confidence level. The operational significance of this multiplicative term, which emerges from the combination of portfolio selection model (1) and portfolio adjustment model (6), is that the responsiveness of investors' bond purchases $\triangle C B_{t}$ to movements in the bond yield $r_{C B, t}$-that is, the partial derivative of $\triangle C B_{t}$ with respect to $r_{C B, t}$-depends positively on the current-quarter flow variable $\Delta W_{t}$. For non-life insurance companies, private pension funds, state and local government retirement funds, and mutual savings banks, the $\left(r_{C B, t} \cdot \Delta W_{t}\right)$ term is the only appearance of the current value of the own yield in the bond demand equation. For life insurance companies and households, the term $\left(r_{\boldsymbol{C B}, t} \cdot W_{t-1}\right)$ also appears in the demand equation, with negative sign and positive sign, respectively.

For all five investor categories other than households, one aspect of these results may at first seem puzzling. Does the absence of the $\left(r_{C B, t} \cdot W_{t-1}\right)$ term in the equations for four investor categories indicate that these investors' bond purchases are totally unresponsive to the own yield if the wealth flow is zero? Does the negative coefficient of the $\left(r_{C B, t} \cdot W_{t-1}^{L}\right)$ term in the life insurance company equation indicate that these companies' bond purchases respond negatively to the own yield if the wealth flow is less than a specific fraction of the existing stock of wealth? The answer to both questions is probably that it is not reasonable to extrapolate the results of estimating a model too far beyond the ob-

\footnotetext{
one-quarter shift to positive net purchases of corporate bonds by other insurance companies in this quarter, just in the midst of a sustained period of negative net purchases.

${ }^{33}$ The private pension fund equation also includes a dummy variable with unit value in 1971:IV and zero value in all other quarters; the flow-of-funds data show an isolated one-quarter shift to positive net purchases of corporate bonds by private pension funds in this quarter, just in the midst of a sustained period of negative purchases.
} 
served range of the data variables. For life insurance companies, for example, the estimated partial derivative of $\Delta C B_{t}^{L}$ with respect to $r_{C B, t}$ that is, the value $\left(0.4550 \Delta W_{t}^{L}-0.003119 W_{t-1}^{L}\right)$-is positive, given the actual values of $\Delta W_{t}^{L}$ and $W_{t-1}^{L}$, for all 56 quarters of the sample period.

All six estimated equations also conform to the portfolio behavior model developed in Sections I and III in that the lagged own-stock term $C B_{t-1}$ in each case has a coefficient $-\theta_{i i}$ which is significantly different from zero, with the expected negative sign, at the 5 percent confidence level. In addition, the own-stock adjustment coefficients are probably of reasonable magnitude for a quarterly model, indicating that private pension funds (which typically manage their portfolios actively and also invest primarily in publicly traded securities) adjust their bond holdings significantly more rapidly than either households or the other four categories of institutional investors.

The remaining aspects of the empirical results require little comment here. The $\$ 496$ million standard error for households is by far the largest among the six estimated demand equations, but this result is not surprising in light of the high variance of the data for this sector which is a residual element of the flow-of-funds accounts. The few nonyield variables, $X_{h}$, $h=1, \ldots, 4$, represent a minimal allowance for some of the more important expectational variables which influence investors' behavior in the corporate bond market; more thorough investigation of these influences remains as an object of further research.

\section{Simulation Results}

As the discussion of Section IV indicates, the empirical results for the six bond demand equations provide support for the hypotheses embodied in the underlying optimal marginal adjustment model of portfolio behavior, including the role of financial flow variables in influencing short-term portfolio adjustments. It remains to examine the performance of the structural model as a whole in explaining short-run movements in the model's jointly determined variable-the long-term bond yield itself.

Figure 3 and Part A of table 3 present simulation results for the sevenequation structural model consisting of the six demand-for-bonds equations presented in Section IV and the market-clearing identity

$$
\begin{aligned}
\Delta C B_{t}^{L}+\Delta C B_{t}^{O}+\Delta C B_{t}^{P}+\Delta C B_{t}^{S}+\Delta C B_{t}^{M}+\Delta C B_{t}^{H}+\Delta C B_{t}^{E X D} \\
=\Delta C B_{t}^{S U P}
\end{aligned}
$$

where $\triangle C B_{t}^{E X D}$ is the net purchases of corporate bonds by investors taken to be exogenous, and $\triangle C B^{S U P}$ is the (exogenous) total net supply of bonds by all issuers. The simulation period is 1960:I-1973:IV. This simulation is fully dynamic in that, after the first quarter of the simulation period, 


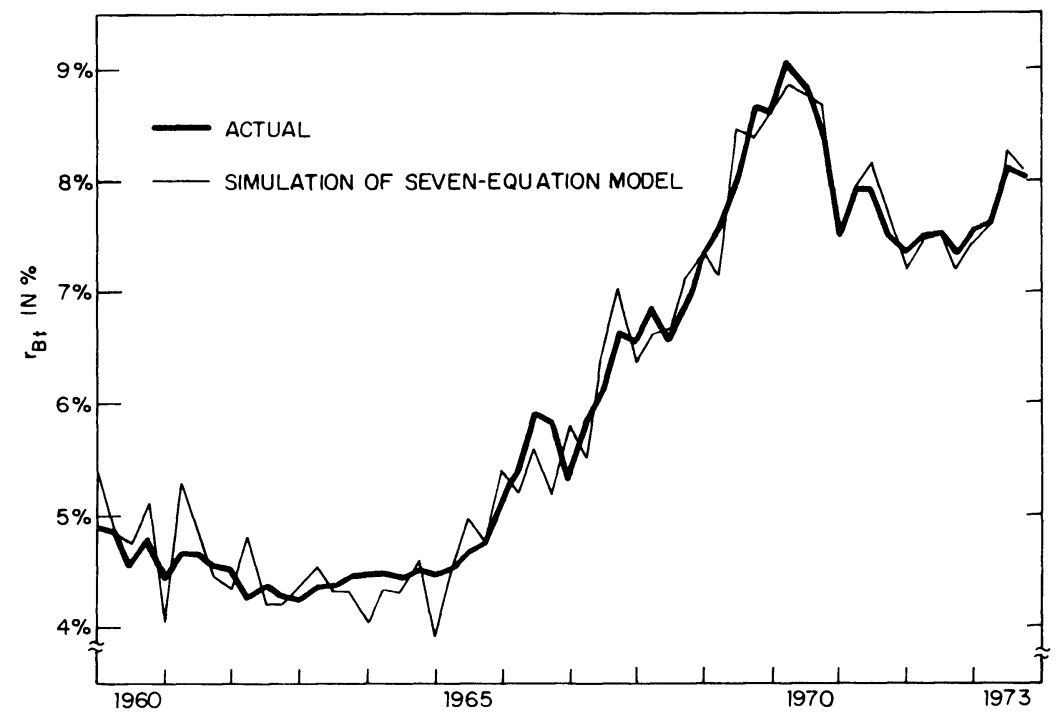

Fig. 3.-Dynamic simulation results for Aa utility new issue yield

the solution uses internally generated values for the lagged own-stock variables $C B_{t-1}$ in all six equations (as well as internally generated values of $r_{C B, t-1}$ and $r_{C B, t-2}$ in variable $\left.X_{4, t}\right) \cdot{ }^{34}$

Part A of table 3 shows the mean and root-mean-square simulation errors for the Aa new-issue utility bond yield $r_{C B}$ and the six net bond purchases variables $\triangle C B$. Figure 3 plots the actual values of $r_{C B}$ against the simulated values. These simulation results show no significant bias for any of the seven endogenous variables. For the six bond purchases variables, the root-mean-square errors are about in line with the standard errors of the estimated equations, indicating that the errors made by individual equations have no observable tendency to compound one another in a dynamic context. For the bond yield itself, the 0.27 percent root-mean-square error is about comparable to the fit achieved by other researchers using the reduced-form term-structure approach. ${ }^{35}$ This

34 To provide at least some limited precaution against the multiple solution problem in simulations of systems of nonlinear simultaneous equations (see Friedman [1971]), the simulations reported here were performed several times with various orderings of the individual equations; the results were urchanged.

${ }^{35}$ Modigliani and Shiller's (1973) preferred equation had SE $=.13$ percent for the less volatile Aaa yield over the sample period 1955:III-1971:II. Reestimating the Modigliani-Shiller equation using the Aa yield and the 1960:I-1973:IV sample period leads to an equation with $\mathrm{SE}=.22$ percent but with the coefficients of the distributed lag on the short-term yield not significantly different from zero. Feldstein and Eckstein's (1970) preferred equation had $\mathrm{SE}=.09$ percent for the Aaa yield over the sample period 1954:I-1969:II. Reestimating the Feldstein-Eckstein equation using the Aa yield and the 1960:I-1973:IV sample period leads to an equation with $\mathrm{SE}=.29$ percent . 
TABLE 3

Dynamic Simulation Results for 1960:I-1973:IV

A. Seven-Equation Strugtural Model with Bond Supply Exogenous

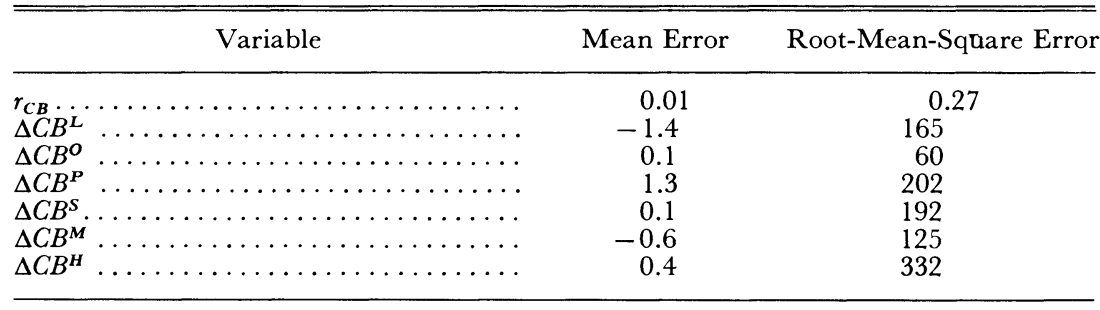

B. Nine-Equation Structural Model with Bond Supply Endogenous

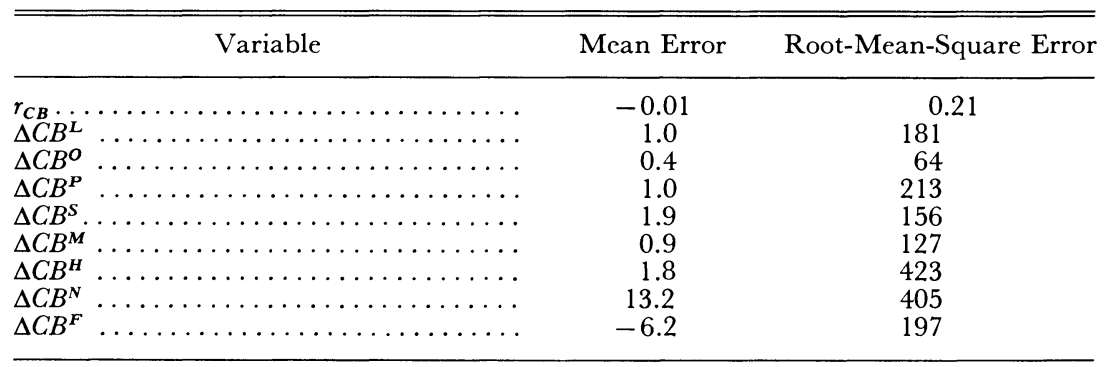

Note. $-{ }_{C B}$ in percent, all $\triangle C B$ in $\$$ million.

within-sample performance seems quite creditable, especially since the methodology of the structural model does not estimate an unrestricted equation directly for the bond yield but, instead, implies an equation for the bond yield which is restricted by the underlying structural hypotheses about portfolio behavior. ${ }^{36}$ In addition, since the focus of this paper is the role of financial flow variables in portfolio behavior, the six estimated demand equations exclude elaborate distributed-lag representations of holding-period yield expectations as well as some nonyield explanatory variables suggested in Friedman (1974).

As is clear from close inspection of figure 3 , the simulated values of the bond yield track the actual values more closely in the second half of the period (RMSE $=0.23$ percent for $1967:$ I-1973:IV) than during the first

Feldstein and Chamberlain's (1973) preferred equation had $\mathrm{SE}=.21$ percent for the Aaa yield over the sample period 1954:I-1971:I.

36 This point is especially relevant to the presence of other long-term yields in the estimated bond demand equations for several investor groups. Including other long-term yields as independent variables in an unrestricted equation with the bond yield as dependent variable would presumably increase greatly such an equation's fit but, in so doing, would in part incorporate spurious correlations. In the context of the structural model, however, the contribution of other long-term yields is restricted to their role in influencing the net purchases variables. 
half ( $\mathrm{RMSE}=0.31$ percent for 1960:I-1966:IV); the appropriate test based on the $F$-statistic $(F=1.71)$ indicates that this difference is significant at the 10 percent confidence level but not at the 5 percent confidence level. Given the "inverted" nature of the system of equations solving for the bond yield, the difference may be due to the greater volatility of the bond yield in more recent years. If so, the ability to track well during periods of greater yield volatility is an attractive feature of the structural model.

Because it takes the total bond supply to be exogenous, this simulation of the seven-equation model cannot capture the supply-demand interaction of a full structural model of the market determination of long-term interest rates. Part B of table 3 presents results for an analogous simulation of the nine-equation structural model consisting of the six demand-forbonds equations presented in Section IV, ${ }^{37}$ the two supply-of-bonds equations presented in Friedman (1976), and the market-clearing identity

$$
\begin{aligned}
\Delta C B_{t}^{L}+\Delta C B_{t}^{O}+\Delta C B_{t}^{P}+\Delta C B_{t}^{S}+ & \Delta C B_{t}^{M}+\Delta C B_{t}^{H}+\Delta C B_{t}^{E X D} \\
& =\Delta C B_{t}^{N}+\Delta C B_{t}^{F}+\Delta C B_{t}^{E X S},
\end{aligned}
$$

where the right-hand-side variables are the net supplies of bonds by (in order) nonfinancial business corporations, finance companies, and issuers taken to be exogenous. ${ }^{38}$

As the $r_{C B}$ error mean and root-mean-square in Part B of table 3 show, the nine-equation structural model with endogenous bond supplies outperforms the seven-equation model in its ability to track the historical movements of the own yield on long-term bonds. There is no significant bias, and the 0.21 percent root-mean-square error seems most creditable. ${ }^{39}$ For the eight bond purchases and issues variables, a small (but not significant) upward bias in net issues by nonfinancial corporations leads to a small (again not significant) downward bias in net issues by finance companies and even smaller uniformly positive upward biases in net purchases by all six investor groups.

Either by themselves or in conjunction with equations for bond supply, therefore, the six demand-for-bonds equations presented in Section IV form the basis of a structural model of long-term interest rate determination which performs well in dynamic simulation tests.

${ }^{37}$ The six demand-for-bonds equations actually used in this simulation were reestimated to allow for the change in the model's set of exogenous variables. The reestimated coefficients differed very little from those reported in Section IV.

${ }^{38}$ As of the end of 1974, nonfinancial business corporations and finance companies, the two endogenous categories of bond issuers, together accounted for over 91 percent of all outstanding corporate bonds issued in the United States.

${ }^{39}$ See again the comparisons in n. 35 above. 


\section{Conclusions}

Two principal conclusions emerge from the empirical work presented in this paper.

First, the individual-equation estimation results support the "optimal marginal adjustment" model of investors' portfolio behavior in the presence of transactions costs which are greater for the reallocation of existing asset holdings than for the initial allocation of new wealth increments. In particular, they support the hypothesis, which underlies the optimal marginal adjustment model, that investable cash flow variables are a significant determinant of investors' short-run asset demands and hence of asset yields as well.

Second, on a methodological level, the full-model dynamic simulation results support the use of a structural model of the determination of longterm interest rates. The implied expression for the long-term bond yield, which is restricted by the estimated structural demand and supply equations, fits the data about as well as do previously developed unrestricted reduced-form term-structure equations. The six investor categories' demand-for-bonds equations perform about as well in dynamic simulations as in individual-equation tests. Given the advantage of a framework consisting of structurally specified demand and supply equations for testing explicit hypotheses about portfolio behavior, therefore, further research on structural models of long-term interest rate determination appears warranted on the basis of these full-model results.

\section{References}

Anderson, W. H. Locke. Corporate Finance and Fixed Investment. Boston: Graduate School Bus. Admin., Harvard Univ., 1964.

Ando, Albert, and Klein, Lawrence R. "Progress of Specifications and Estimation of a Model for Flow of Funds Accounts." Mimeographed. Univ. Pennsylvania, 1975.

Ando, Albert, and Modigliani, Franco. "Some Reflections on Describing Structures of Financial Sectors." In The Brookings Model: Perspective and Recent Developments, edited by G. Fromm and L. R. Klein. Amsterdam: NorthHolland, 1975.

Board of Governors of the Federal Reserve System. Flow of Funds Accounts 1945-72. Washington: Board Governors Federal Reserve System, 1973.

Bosworth, Barry, and Duesenberry, James S. "A Flow of Funds Model and Its Implications." In Issues in Federal Debt Management. Boston: Federal Reserve Bank of Boston, 1973.

Brainard, William C., and Tobin, James. "Pitfalls in Financial Model-Building." A.E.R. 57 (May 1968): 99-122.

$\rightarrow$ Brundy, James M., and Jorgenson, Dale W. "Efficient Estimation of Simultaneous Equations by Instrumental Variables." Rev. Econ. and Statis. 53 (August 1971): 207-24.

$\rightarrow$ Culbertson, J. M. "The Term-Structure of Interest Rates." Q.J.E. 71 (November 1957): 485-517. 
De Leeuw, Frank. "A Model of Financial Behavior." In The Brookings Quarterly Econometric Model of the United States, edited by J. S. Duesenberry et al. Chicago: Rand McNally, 1965.

Duesenberry, James S. "The Portfolio Approach to the Demand for Money and Other Assets." Rev. Econ. and Statis. 65 (February 1963) : 9-24.

Fair, Ray C., and Malkiel, Burton G. "The Determination of Yield Differentials between Debt Instruments of the Same Maturity." J. Money, Credit and Banking 3 (November 1971): 733-49.

Feldstein, Martin, and Chamberlain, Gary. "Multimarket Expectations and the Rate of Interest." J. Money, Credit and Banking 5 (November 1973) : 873-902.

$\rightarrow$ Feldstein, Martin, and Eckstein, Otto. "The Fundamental Determinants of the Interest Rate." Rev. Econ. and Statis. 52 (November 1970): 363-75.

$\rightarrow$ Friedman, Benjamin M. "Econometric Simulation Difficulties: An Illustration." Rev. Econ. and Statzs. 53 (November 1971): 381-84.

- "A Structural Model of the Long-Term Corporate Debt Market." Mimeographed. Harvard Univ., 1974.

- "Substitution and Expectation Effects on Long-Term Borrowing Behavior and Long-Term Interest Rates." Mimeographed. Harvard Univ., 1976.

Friedman, Milton. "The Quantity Theory of Money: A Restatement." In Studies in the Quantity Theory of Money, edited by M. Friedman. Chicago: Univ. Chicago Press, 1956.

Fromm, Gary, and Sinai, Allen. "A Policy Simulation Model of Deposit Flows, Mortgage Sector Activity, and Housing." Mimeographed. Data Resources Inc., 1975.

Goldfeld, Stephen M. Commercial Bank Behavior and Economic Activity. Amsterdam: North-Holland, 1966.

- "An Extension of the Monetary Sector." In The Brookings Model: Some Further Results, edited by J. S. Duesenberry et al. Chicago: Rand McNally, 1969. Hendershott, Patric H. "A Flow-of-Funds Model: Estimates for the Non-Bank Finance Sector." J. Money, Credit and Banking 3 (November 1971) : 815-32.

Hendershott, Patric H., and Lemmon, Richard C. "A Flow of Funds Model: First Estimates and Forecasts." American Statistical Association Journal Proceedings (1973), business and economics section, pp. 112-21.

Hicks, John R. Value and Capital. London: Oxford Univ. Press, 1939.

Kessel, Reuben A. "The Cyclical Behavior of the Term Structure of Interest Rates." In Essays on Interest Rates, edited by J. Guttentag. Vol. 2. New York: Columbia Univ. Press, 1971.

Kopcke, Richard W. "An Econometric Analysis of Household Demand Behavior for Financial Assets." Ph.D. dissertation, Harvard Univ., 1973.

Ladenson, Mark L. "Pitfalls in Financial Model Building: Some Extensions." A.E.R. 61 (March 1971): 179-86.

Malkiel, Burton Gordon. The Term Structure of Interest Rates. Princeton, N.J.: Princeton Univ. Press, 1966.

Meiselman, David. The Term Structure of Interest Rates. Englewood Cliffs, N.J.: Prentice-Hall, 1962.

Modigliani, Franco. "The Dynamics of Portfolio Adjustment and the Flow of Savings through Financial Intermediaries." In Savings Deposits, Mortgages and Housing, edited by E. M. Gramlich and D. M. Jaffee. Lexington, Mass.: Heath, 1972.

Modigliani, Franco, and Shiller, Robert J. "Inflation, Rational Expectations, and the Term Structure of Interest Rates." Economica 40 (February 1973): 12-43.

. "New Issues and the Term-Coupon Structure of Bond Yields." Mimeographed. M.I.T., 1974. 
$\rightarrow$ Modigliani, Franco, and Sutch, Richard. "Innovations in Interest Rate Policy." A.E.R. 56 (May 1966) : 178-97.

$\rightarrow-$. "Debt Management and the Term Structure of Interest Rates: An Empirical Analysis of Recent Experience." J.P.E. 75, no. 4 (August 1967): 569-89.

Shapiro, Eli, and Wolf, Charles R. The Role of Private Placements in Corporate Finance. Boston: Harvard Univ., Graduate School Bus. Admin., 1972.

Silber, William L. Portfolio Behavior of Financial Institutions. New York: Holt, Rinehart \& Winston, 1970.

Smith, Gary. "Pitfalls in Financial Model Building: A Clarification." A.E.R. 65 (June 1975) : 510-16.

Smith, Gary, and Brainard, William. "Estimation of the Savings Sector in a Disequilibrium Model." Mimeographed. Yale Univ., 1974. 